\title{
ĐĂC ĐIỂM RỐI LOẠN CHỨC NĂNG TÌNH DỤC Ở NGƯỜI BÊNNH NAM RỐI LOAN LO ÂU LAN TỎA
}

\author{
Nguyễn Văn Giáp ${ }^{1}$, Trần Thị Hà $\mathrm{An}^{2}$, Nguyễn Thị Hải Hà ${ }^{3}$
}

\section{TÓM TẮT}

Bối cảnh: Rối loạn lo âu lan tỏa là một rối loan đặc trưng bởi lo lắng quá mức, mạn tính, không thể kiểm soát được, có tính chất lan tỏa, tản mạn, không khu trú vào một sự kiện hoàn cảnh đặc biệt nào ở xung quanh hoặc có liên quan với những sự kiện đã qua không còn tính thời sự nữa. Rối loạn này thường liên quan tới stress trường diễn, tiến triển thay đổi nhưng có xu hướng mạn tính. Các nghiên cứu cho thấy tỉ lệ rối loạn chức năng tình dục cao ở người bệnh lo âuu lan toả. Mục tiêu nghiên cứu: Mô tả đặc điểm rối loạn chức năng tình dục ở người bệnh nam rối loạn lo ẩu lan tỏa điều trị nội trú tại Viện Sức khỏe Tâm thần Bệnh viện Bạch Mai. Đối tượng và phương pháp nghiên cứu: Nghiên cứu mồ tả cắt ngang 60 bệnh nhân rối loạn lo âu lan tỏa điều trị nôi trú tại Viện Sức khỏe Tâm thần Bệnh viện Bạch Mai từ tháng 07/2020 đến tháng 07/2021. Kết quả: độ tuổi

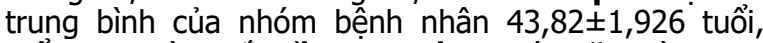
tuổi trung bình bắt đâuu hoạt đônng chức năng tình dục

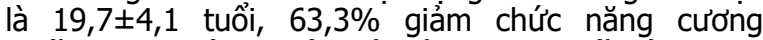
chiếm, $70 \%$ bênh nhân có giảm ham muốn tình dục, $75 \%$ bệnh nhẩn báo cáo thời gian xuất tinh nhanh hơn bình thường. Kết luâan: Rối loạn chức năng tình dục ở bệnh nhân rối loạn lo âu lan tỏa xuất hiện với tỉ lệ cao, với biểu hiện giảm ham muốn, chức năng cương suy giảm, thời gian xuất tinh rút ngắn, là vấn đề cần được quan tâm nhiều hơn khi điều trị các bệnh nhân rối loạn lo âu lan tỏa.

Tư khóa: rối loạn lo âu lan tỏa, rối loạn chức năng tình dục, đặc điểm lâm sàng.

\section{SUMMARY}

\section{THE CHARACTERISTICS OF SEXUAL}

\section{DYSFUNCTION IN MALE PATIENTS WITH} GENERALIZED ANXIETY DISORDER

Background: Generalized anxiety disorder is characterized by worries excessive, chronic, uncontrollable, pervasive and scattered for no obvious reasons or related to past events. This disorder is often associated with chronic stresses. It's prognosis usually fluctuates and tends to be chronic. Previous studies showed the high rates of sexual dysfunction in patients with generalized anxiety disorder. Research objectives: To describe the characteristics of sexual dysfunction in male inpatients with generalized anxiety

\footnotetext{
${ }^{1}$ Dai hoc Y Hà Nội

'2Viện Sức khỏe Tâm thần, Bệnh viện Bạch Mai

${ }^{3}$ Viện Sức khỏe nghề nghiệp và môi trường

Chịu trách nhiệm chính: Nguyễn Văn Giáp

Email: anhgiap1511@gmail.com

Ngày nhận bài: 27.7.2021

Ngày phản biên khoa họ: 28.9.2021

Ngày duyệt bài: 5.10 .2021
}

disorder who were treated at the Mental Health Institute, Bach Mai Hospital. Subjects and research methods: A cross-sectional descriptive study of 60 inpatients with generalized anxiety disorder at the Mental Health Institute, Bach Mai Hospital from August 2020 to July 2021. Results: the mean age was $43.82 \pm 1.926$ years old, the mean age of starting sexual activities was $19.7 \pm 4.1$ years old, decreased erectile function was of $63.3 \%$ patients, $70 \%$ of the patients had a decreased sex desire, $75 \%$ of patients reported faster-than-normal ejaculation time. Conclusion: Sexual dysfunction in male patients with generalized anxiety disorder which was very common is characterized by manifestations including decreased sex desire, impaired erectile function, and shortened ejaculation time. It's the problem that needs to be paid more attention when treating patients with generalized anxiety disorder.

Keywords; generalized anxiety disorder, sexual dysfunction, clinical features.

\section{I. ĐĂT VẤN ĐỀ}

Rối loạn lo âu lan tỏa được đặc trưng bởi tình trạng lo lắng quá mức không kiểm soát được, kéo dài trên 6 tháng, kèm theo các biểu hiện căng thẳng về tâm thần, về vận động và rối loạn thần kinh thực vật. Đây là một rối loạn gặp phồ biến trong lẩm sàng tâm thần học, chiếm tỷ lệ $37 \%$ trong các rối loạn lo âu được điều trị nội trú. Ở Mỹ, tỉ lệ mắc trong cả đời của rối loạn lo âu lan tỏa là $5,7 \%{ }^{1}$, phổ biển ở nữ hơn nam. Ngoài các triệu chứng về thần kinh thực vật, triệu chứng liên quan đến vùng ngực và bụng, các triệu chứng liên quan đến hoạt động tâm thần và nhiều triêu chứng khác đã được mô tả trong ICD 10 , thì vấn đề rối loạn chức năng tình dục ở bệnh nhân rối loạn lo âu lan tỏa cũng cần được quan tâm nhiêu hơn khi mà tỉ lệ này lển tới $64 \%^{2}$, tuy nhiên ở Việt Nam vấn đề chức năng tình dục còn chưa được thực sự quan tâm ơ những bệnh nhân này.

Tình dục là một trong các nhu câu cơ bản của con người cũng như ăn uống ngủ, tuy nhiên các rối loạn tình dục có thể xuất hiện làm bản thân người bệnh và đối tác của họ không thể thỏa mãn nhu cầu tình dục dẫn đến mối quan hệ không hạnh phúc, lo lắng căng thẳng làm nặng lên bệnh lý rối loạn lo âu lan tỏa cũng như tuân thủ điều trị.

Tại Việt Nam có nhiều bệnh nhân được chẩn đoán rối loạn lo âu lan tỏa, tuy nhiên chưa có nghiên cứu nào về vấn đề rối loạn chức năng 
tình dục do đó chúng tôi thực hiện nghiên cứu: "Đặc điểm rối loạn chức năng tình dục ở người bệnh nam rôi loạn lo âu lan tóa điều trị nội trú tại Viện Sức khỏe Tâm thần"với mục tiêu:

Mô tả đặc điểm rối loạn chức năng tình dục ở người bệnh nam rối loạn lo âu lan tỏa điều trị nộl trú tại Viện Sức khỏe Tâm thần BV Bạch Mai.

\section{II. ĐỐI TƯƠ'NG VÀ PHƯƠNG PHÁP NGHIÊN CỨU}

2.1. Đối tượng nghiên cứu: 60 bệnh nhân được chẩn đoán xác định mắc rối loạn lo âu lan tỏa theo tiêu chuẩn của ICD -10 , điều trị nội trú tại Viện Sức khỏe Tâm thần, Bệnh viên Bạch Mai từ tháng 07/2020 đến tháng 07/2021.

2.2. Tiêu chuẩn loại trừ: Bệnh nhân và người nhà không đồng ý tham gia nghiên cứu, bệnh nhân có tiền sử rối loạn chức năng tình dục. Bệnh nhân mắc các bệnh cơ thể nặng.

2.3. Phương pháp nghiên cứu: Phương pháp mô tả cắt ngang. Số liệu được xử lý bằng phần mềm SPSS 20.0.

2.4. Đạo đức nghiên cứu: Số liệu được mã hoá nhằm giữ bí mật thông tin cho bệnh nhân. Đây là nghiên cứu mô tả không can thiệp chẩn đoán và điều trị, không ảnh hưởng đến sức khỏe người bệnh. Bệnh nhân và người nhà đồng ý tham gia nghiên cứu.

\section{KẾT QUẢ VÀ BÀN LUÂ̂N}

3.1. Đăc điểm chung của nhóm nghiên cứu

Bảng 3.1. Đặc điểm chung của nhóm bệnh nhân nghiên cứu ( $N=60)$

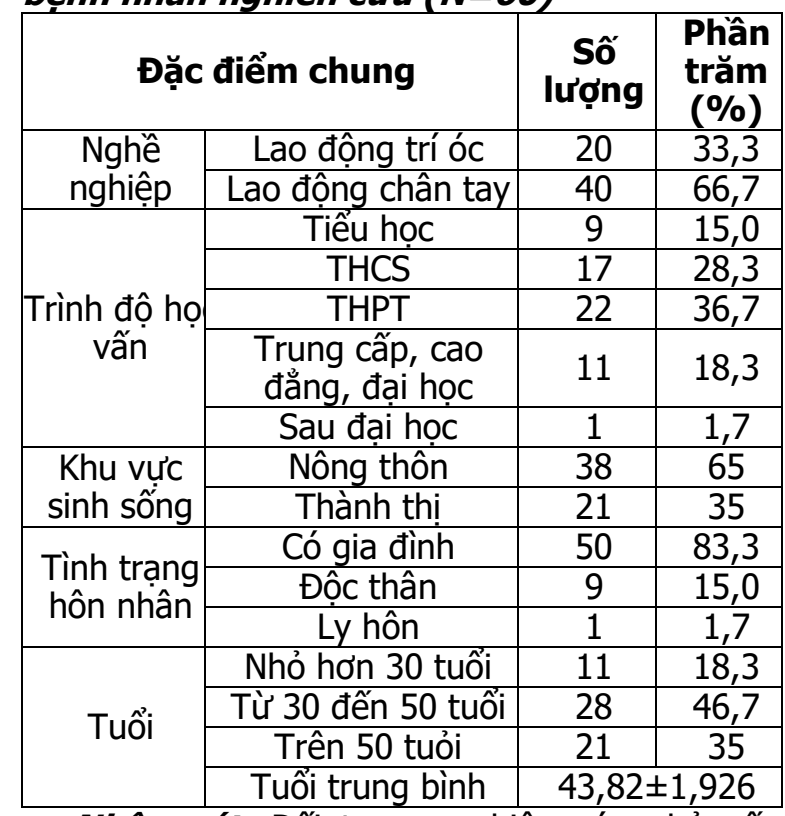

Nhận xét: Đối tượng nghiên cứu chủ yếu làm các công việc thiên về lao động thể chất với tỉ lệ 66,7\% với trình độ học vấn chủ yếu từ THPT với tỉ lệ $80 \%$, khu vực sinh sống chủ yếu phân bố ở vùng nông thông với tỉ lệ $65 \%$. Đối tượng nghiên cứu chủ yếu là đã lập gia đình với tî lệ $85 \%$. Độ tuổi trung bình là khoảng 44 tuổi, tương đương với nghiên cứu của Trần Nguyễn Ngọc và cộng sự năm 2018 tuổi trung bình là khoảng $43^{3}$.

Bảng 3.2: Độ tuổi bắt đầu hoạt động tinh duc $(N=60)$

\begin{tabular}{|c|c|c|}
\hline Nhóm tuổi & $\begin{array}{c}\text { Số } \\
\text { lượng }\end{array}$ & $\begin{array}{c}\text { Phân trăm } \\
\text { (\%) }\end{array}$ \\
\hline Từ dưới 18 tuối & 28 & 46,7 \\
\hline Trên 18 đến 25 tuối & 27 & 45,0 \\
\hline Trên 25 tuối & 5 & 8,3 \\
\hline Trung bình & $19,7 \pm 4,1$ tuối \\
\hline
\end{tabular}

Nhânn xét: Tuối bắt đầu hoạt động tình dục của nhóm đối tượng nghiên cứu thường từ 18 tuổi trở xuống khi chiếm tỉ lệ xấp xỉ 50\%, khi đối tượng nghiên cứu đang ở tuổi học trung học cơ sở và trung học phổ thông, chủ yếu là hoạt động tự thỏa mãn tình dục.

Bảng 3.3. Tiền sử hoạt động tình dục $(N=60)$

\begin{tabular}{|c|c|c|}
\hline $\begin{array}{c}\text { Tiền sử hoạt động } \\
\text { tình dụcc }\end{array}$ & $\begin{array}{c}\text { Số } \\
\text { lượng }\end{array}$ & $\begin{array}{c}\text { Phần trăm } \\
\mathbf{( \% )}\end{array}$ \\
\hline QHTD với người khác & 30 & 50,0 \\
\hline Tự thỏa mãn tình dục & 3 & 5,0 \\
\hline Cả hai & 27 & 45,0 \\
\hline
\end{tabular}

Nhận xét: Đối tượng nghiên cứu chủ yếu đã quan hệ tình dục với người khác, bên cạnh việc quan hể tình dục với người khác chiếm tới $95 \%$ bệnh nhân, đối tượng nghiên cứu còn có hoạt động tự thỏa mãn tình dục với tỉ lệ khá cao $50 \%$ đối tượng nghiên cứu. Phù hợp với đặc điểm nghiên cứu là các bệnh nhân nam độ tuổi trung bình 43,8 tuổi, độc thân chiếm 16,7\%.

3.2 Đặc điểm rối loạn chức năng tình dục ở nhóm bênh nhân nghiên cứu

Bảng 3.4: Phân loai rôi loạn chức năng tinh dyc theo thang Arizona $(N=60)$

\begin{tabular}{|c|c|c|}
\hline Phân loại & Số lượng & $\begin{array}{c}\text { Phân } \\
\text { trăm (\%) }\end{array}$ \\
\hline $\begin{array}{c}\text { Có rối loạn chức } \\
\text { năng tình dục }\end{array}$ & 29 & 48,3 \\
\hline $\begin{array}{c}\text { Không có rối loạn } \\
\text { chức năng tình dục }\end{array}$ & 31 & 51,7 \\
\hline
\end{tabular}

Nhận xét: Thang đo trải nghiệm tình dục Arizona đánh giá ham muốn tình dục, hưng phẩn tình dục, chức năng cương dương và khoái cảm tình dục, qua bảng trên ta thấy tỉ lệ có rối loạn theo thang đo này chiếm $51,7 \%$ tương đương với nghiên cứu của Kendukar và cộng sự tỉ lệ nam giới mắc lo âu lan tỏa có rối loạn chức năng tình dục là $56,2 \%{ }^{4}$. 
Bảng 3.5. Thay đổi trong hoạt động tình $\operatorname{duc}(\mathrm{N}=60)$

\begin{tabular}{|c|c|c|c|}
\hline \multicolumn{2}{|c|}{ Đặc điểm } & \multirow{2}{*}{$\begin{array}{c}\begin{array}{c}\text { Số } \\
\text { lượng }\end{array} \\
42 \\
\end{array}$} & \multirow{2}{*}{\begin{tabular}{|c|}
$\begin{array}{c}\text { Phần trăn } \\
(\%)\end{array}$ \\
70 \\
\end{tabular}} \\
\hline Thay đối & Giảm ham muốn & & \\
\hline $\begin{array}{c}\text { ham muốn } \\
\text { tình duc }\end{array}$ & Không thay đổi & 18 & 30 \\
\hline \multirow{3}{*}{$\begin{array}{l}\text { Chức năng } \\
\text { cương }\end{array}$} & $\begin{array}{l}\text { Cânn nhiều kích } \\
\text { thích hơn }\end{array}$ & 34 & 56,7 \\
\hline & $\begin{array}{l}\text { Khó duy trì trang } \\
\text { thái cương }\end{array}$ & 36 & 60,0 \\
\hline & $\begin{array}{c}\text { Không thế đạt } \\
\text { trạng thái cương } \\
\text { hoàn toàn }\end{array}$ & 38 & 63,3 \\
\hline \multirow{3}{*}{$\begin{array}{l}\text { Thay đổi } \\
\text { xuất tinh }\end{array}$} & Nhanh hơn & 45 & 75 \\
\hline & $\begin{array}{l}\text { Khả năng kiểm } \\
\text { soát xuất tinh khó } \\
\text { hơn bình thường }\end{array}$ & 43 & 71,7 \\
\hline & Chậm hơn & 0 & 0 \\
\hline
\end{tabular}

Nhận xét: Quá trình hoạt động tình dục thường được chia thành 4 giai đọan, giai đoạn hưng phấn, giai đoạn cao nguyên, giai đoạn cực khoái, giai đoạn thoái trào ${ }^{5}$. Tuy nhiên, quá trình hoạt động tình dục là quá trình liên tục, sự thay đổi của 1 trong 4 giai đoạn đều gây ảnh hưởng đến kết quả chung của quá trình hoạt động tình dục. Qua nghiên cứu nhận thây có đến $70 \%$ bệnh nhân có biểu hiện giảm ham muốn tình dục, do nhiêu yếu tố khác nhau như mệt mỏi ở những bệnh nhân có biểu hiện trầm cảm, lo lắng quá mức các vấn đề trong cuộc sống, các triệu chứng cơ thể hoặc các yếu tố không thay đổi được như tuổi tác, đặc điểm tính cách, theo một cuộc khảo sát nhân khẩu học được thực hiện tại Hoa Kỳ vào năm 2004, với sự tham gia của 1.455 nam giới từ $57-85$ tuổi, cho thấy $28 \%$ nam giới cho biết thiếu ham muốn tình dục, trong đó $65 \%$ cho biết là bị làm phiền bởi sự mất ham muốn của hộ. Qua nghiên cứu ta thấy có khoảng $60 \%$ bệnh nhân có chức năng cương thay đổi, chủ yểu là suy giảm chức năng cương với biểu hiện chủ yếu lá cần nhiều kích thích hơn, khó duy trì trạng thái cương và không thể đạt trạng thái cương cứng hoàn toàn.

Tất cả các rối loạn chức năng tình dục, ngay cả do nguyên nhân cơ thể được ghi nhận nhiều nhất (chẳng hạn như rối loạn cương dương liên quan đến bênh tiểu đường), đều gây căng thẳng và có thể dẫn đến rối loạn tâm thần. Lo lắng về hiệu suất là một vấn đề phổ biến ở nam giới bị rối loạn chức nắng tình dục, thường dẫn đển việc trốn tránh quan hệ tình dục, mất lòng tự trọng và trầm cảm? . Suy giảm chất lượng cuộc sống và làm nặng thêm triệu chứng lo âu ở bệnh nhân.
Qua nghiên cứu nhận thấy có đến $75 \%$ bệnh nhân có sự suy giảm thời gian xâm nhập âm đạo trước xuất tinh. Tuy nhiên theo một nghiên cứu của Rajkuma và cộng sự thì có khoảng 35,71\% bệnh nhân xuất tinh sớm có biểu hiện lo âu trước hoặc trong qua trình giao hợp8.

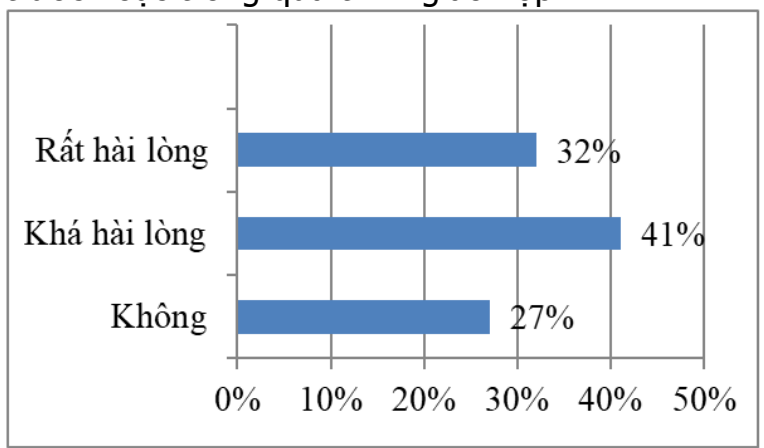

Biểu đồ 3.1: Hài lòng sau quá trinh hoạt dộng tình dục

Nhân xét: Tỉ lể không hài lòng sau quá trình hoạt động tình dục chiếm $27 \%$, do nhiều nguyên nhẩn khác nhau như không hài lòng về khả năng cương, thời gian trước xuất tinh, khoái cảm tình duc, tuy nhiên tỉ lệ này khá thấp so với các biểu hiên thay đổi chức năng tình dục đã nhận xét ở trển, phần nhiều nghĩ đến sự chấp nhận của đối tượng nghiên cứu về khả năng hoạt động tình dục như là một hoạt động bản năng, chứ chưa thực sự quan tâm đến các lợi ích cũng như các sự ảnh hưởng của nó và quan tâm đúng mức đến chức năng tình dục.

\section{KẾT LUÂN}

Rối loạn chức năng tình dục ở bệnh nhân rối loạn lo âu lan tỏa xuất hiện với tỉ lệ cao, với biểu hiện giảm ham muốn, chức năng cương suy giảm, thời gian xuất tinh rút ngắn, là vấn đề cần được quan tâm nhiều hơn khi điều trị các bệnh nhẩn rối loạn lo âu lan tỏa.

\section{TÀI LIẸU THAM KHẢO}

1. Weisberg RB. Overview of Generalized Anxiety Disorder: Epidemiology, Presentation, and Course. J Clin Psychiatry.:6.

2. Clayton AH, Durgam $S$, Tang $X$, Chen $C$, Ruth A, Gommoll C. Characterizing sexual function in patients with generalized anxiety disorder: a pooled analysis of three vilazodone studies. Neuropsychiatr Dis Treat. 2016;12:1467-1476. doi:10.2147/NDT.S103408

3. Trân Nguyễn Ngọc (2018). Đánh giá hiệu quả điều trị rối loan lo âu lan tỏa bằng liếu pháp thư giãn - luyện tập, Luận án Tiến sỹ, Trường Đại Học Y Hà Nôii.

4. Kendurkar A, Kaur B. Major depressive disorder, obsessive-compulsive disorder, and generalized anxiety disorder: do the sexual dysfunctions differ? 
Prim Care Companion J Clin Psychiatry. 2008;10(4): 299-305.

5. Adair LE. Four-Stage Model of the Sexual Response. In: Weekes-Shackelford V, Shackelford TK, Weekes-Shackelford VA, eds. Encyclopedia of Evolutionary Psychological Science. Springer International Publishing; 2016:1-5. doi:10.1007/978-3-319-16999-6 1892-1

6. DeRogatis L, Rosen RC, Goldstein I, Werneburg B, Kempthorne-Rawson J, Sand M. Characterization of Hypoactive Sexual Desire
Disorder (HSDD) in Men. The Journal of Sexual Medicine. 2012;9(3):812-820. doi:10.1111/j.17436109.2011.02592.x

7. Yafi FA, Jenkins $L$, Albersen $\mathbf{M}$, et al. Erectile dysfunction. Nat Rev Dis Primers. 2016;2(1):16003. doi:10.1038/nrdp.2016.3

8. Rajkumar RP, Kumaran AK. The Association of Anxiety With the Subtypes of Premature Ejaculation: A Chart Review. Prim Care Companion CNS Disord. 2014;16(4):10.4088/PCC.14m01630. doi:10.4088/PCC. $14 \mathrm{~m} 01630$

\title{
ĐĂC ĐIỂM LÂM SÀNG RỐI LOẠN Ý THỨC Ở BÊ̂NH NHÂN CHẤN THƯƠ'NG SỌ NÃO
}

\author{
Nguyễn Hương Quỳnh ${ }^{1}$, Nguyễn Văn Tuấn ${ }^{1,2}$, \\ Dương Đại Hà ${ }^{1,3}$, Dương Anh Tài ${ }^{1}$
}

\section{TÓM TẮT}

Đă̆t vấn đê: Rối loạn ý thức là môt trong những biểu hiên hay gặp nhất trong những rối loan tâm thần cấp xuẩt hiện sau chấn thương sọ não. Nghiên cứu các rối loạn ý thức góp phần trong việc điều trị cho bệnh nhân chấn thương sọ não (CTSN) tốt hơn. Mục tiều: Mô tả đăc điểm lâm sàng rối loạn ý thức ở bênh nhân chấn thương sọ não. Đối tượing và phương pháp nghiên cứu: Nghiên cứu mô tả cắt ngang thực hiện trên 76 bệnh nhân chấn thương sọ não điêu trị tại khoa Phẫu thuât thần kinh bênh viện Viêt Đức từ tháng 10/2020 đến tháng 07/2021. Kết quả: Tỉ lê bênh nhân nam giới chiếm phân lớn $(82,89 \%)$, tuổi trung bình $39,54 \pm 18,04$ và nguyên nhân chấn thương sọ não chủ yếu là tai nạn giao thông. Có 42 bệnh nhân có rối loạn ý thức trong tổng số 76 bệnh nhân nghiên cứu, bao gồm các rối loạn định hướng không gian $(47,4 \%)$, rối loạn định hướng thời gian $(47,4 \%)$, rối loạn định hướng bản thân $(33,7 \%)$ và rối loạn định hướng xung quanh $(44,2 \%)$.

Tư khoá: rối loạn ý thức, chấn thương sọ não.

\section{SUMMARY \\ CLINICAL FEATURES OF DISORDER OF CONSCIOUSNESS IN PATIENTS WITH TRAUMATIC BRAIN INJURY}

Background: Disorder of consciousness is one of the most common acute mental disorder in traumatic brain injury. The evalution of its symptoms helps prognosis and support treatment. Research objective: Describe the clinical characteristics of disorder of consciousness in patients with traumatic

${ }^{1}$ Đai hoc Y Hà Nọi

${ }^{2}$ Việt Sức khoẻ Tâm thần, Bệnh viện Bạch Mai

${ }^{3}$ Bênhh viện Hữu nghi Việt Đức

Chịu trách nhiệm chính: Nguyễn Hương Quỳnh

Email: linkinpark28028@gmail.com

Ngày nhận bài: 30.7.2021

Ngày phản biện khoa học: 27.9.2021

Ngày duyệt bài: 4.10.2021 brain injury. Subjects and research methods: A cross-sectional study was conducted on 76 patients with traumatic brain injury, treated at the Departement of Neurosurgery of Viet Duc University Hospital from October 2020 to July 2021. Result: The study subjects are mainly male $(82,89 \%)$, the average age is $39,54 \pm$ 18,04 and $81,6 \%$ causes is traffic crashes. There were 42 patients with disorder of consciousness out of 76 patients with traumatic brain injury, accounted $55,3 \%$.

Keywords: disorder of consciousness, disorientation, traumatic brain injury.

\section{I. ĐĂT VẤN ĐỀ}

Chấn thương sọ não là loại chấn thương rất thường gặp trong thực hành lâm sàng, điều trị tốn kém, di chứng và tử vong cao. Tại Hoa Kỳ hàng năm có 1,5 tới 8 triệu người bị chấn thương sọ não, trong đó khoảng 52.000 bệnh nhân tử vong và 100.000 bệnh nhân mang di chứng suốt đời[1].

Rối loạn ý thức là một trong những biểu hiện hay gặp nhất trong những rối loạn tâm thân cấp xuất hiện sau chấn thương sọ não. Người bệnh bị rối loạn ý thức có thể xuất hiện những triệu chứng như mất tỉnh táo, rối loạn định hướng, rối loạn cảm xúc, rối loạn hành vi, giảm tập trung chú ý,... thậm chí có thể hôn mê. Nghiên cứu các rối loạn ý thức góp phân trong việc điều trị cho bệnh nhân chấn thương sọ não tốt hơn. Vì vậy chúng tôi tiến hành nghiên cứu với mục tiêu: Mô tả đặc điểm lâm sàng rối loạn ý thức ở bệnh nhân chấn thương sọ não.

II. ĐỐI TƯỢNG VÀ PHƯƠNG PHÁP NGHIÊN CỨU

2.1 Đối tượng nghiên cứu: Nghiên cứu 76 bệnh nhân được chẩn đoán chấn thương sọ não điều trị nội trú tại khoa phẫu thuật thân kinh bệnh viện Việt Đức từ tháng 10/2020 đến tháng 7/2021. Bệnh nhân và người nhà đông ý tham 